\title{
ABSTRACTS
}

\section{A STUDDY OF THE ADMISSION SYSTEM OF A HIGH SCHOOL}

\author{
by \\ Giyoo Hatano \\ University of Tokyo
}

The importance to the individual and society of admission standards seems chiefly due to the fact that the academic career of an individual determines his whole future, namely his professional and social life in general. Thus, since the success or failure of the admission into a school is of primary importance to every adolescent, the screening of applicants must be all the more valid and impartial.

This study aimed to examine the validity and impartiality of the screening system of a senior high school and to compare of the predictive power of each instrument employed therein, taking as criteria the academic records in five major school subjects at the end of the first term. The subjects included some 350 tenth-graders of a senior high school in Yokohama, Kanagawa Prefecture. The validity coefficient of the screening system employed by the said high school, consisting of the grand total of two kinds of achievement test and academic records (5point marks) in five major school subjects in the eighth and ninth grades (the second and third years in Japanese junior high school), was found to be as high as 840 , and even up to .897 when corrected for selection. However, when we averaged the differences between the estimated criterion values (by the regression equation) and the actual values achieved by the graduates of the four junior high school, we found these means were significantly different. That is, there was a tendency for all the graduates of one junior high school to be evaluated more highly in the screening and accordingly admitted more easily into the high school, compared with those of other junior high schools. This bias seems to be caused mainly by the difference in the standards of assessment of different school's, however, the possible effect of tutoring for the examination may not be disregarded.

As for the predictive power of each instrument, the academic records in junior high school (scaled on an achievement test) correlated more highly with the criterion than the two kinds of achievement tests and showed the greatest beta weight in the battery including the two achievement tests. It would be difficult, however, to make a valid and impartial selection solely on the basis of the academic records in junior high school, abolishing wholly the achievement test which is often criticised for its undesirable effect on education. Therefore, it may be said, from the view-point of validity, that an achievement test is not only necessary for the scaling purpose, but also useful as a direct instrument for screening.

* We owe editing of English abstracts in this issue to Dr. Ray Simpson of the University of Illinois 